\title{
Structure of branching enzyme- and amylomaltase modified starch produced from well-defined amylose to amylopectin substrates
}

Sorndecha, Waraporn; Sagnelli, Domenico; Meier, Sebastian; Jansson, Anita M.; Lee, Byung-Hoo ; Hamaker, Bruce R. ; Rolland-Sabaté, Agnès ; Hebelstrup, Kim H.; Tongta, Sunanta; Blennow, Andreas

Published in:

Carbohydrate Polymers

Link to article, DOI:

10.1016/j.carbpol.2016.06.097

Publication date:

2016

Document Version

Peer reviewed version

Link back to DTU Orbit

Citation $(A P A)$ :

Sorndecha, W., Sagnelli, D., Meier, S., Jansson, A. M., Lee, B-H., Hamaker, B. R., Rolland-Sabaté, A., Hebelstrup, K. H., Tongta, S., \& Blennow, A. (2016). Structure of branching enzyme- and amylomaltase modified starch produced from well-defined amylose to amylopectin substrates. Carbohydrate Polymers, 152, 51-61. https://doi.org/10.1016/j.carbpol.2016.06.097

\section{General rights}

Copyright and moral rights for the publications made accessible in the public portal are retained by the authors and/or other copyright owners and it is a condition of accessing publications that users recognise and abide by the legal requirements associated with these rights.

- Users may download and print one copy of any publication from the public portal for the purpose of private study or research.

- You may not further distribute the material or use it for any profit-making activity or commercial gain

- You may freely distribute the URL identifying the publication in the public portal 


\section{Accepted Manuscript}

Title: Structure of branching enzyme- and amylomaltase modified starch produced from well-defined amylose to amylopectin substrates

Author: Waraporn Sorndech Domenico Sagnelli Sebastian Meier Anita M. Jansson Byung-Hoo Lee Bruce R. Hamaker

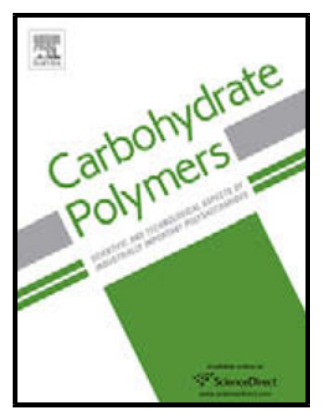
Agnès Rolland-Sabaté Kim H. Hebelstrup Sunanta Tongta Andreas Blennow

PII:

DOI:

Reference:

To appear in:

Received date:

Revised date:

Accepted date:
S0144-8617(16)30772-X http://dx.doi.org/doi:10.1016/j.carbpol.2016.06.097

CARP 11282

Please cite this article as: Sorndech, Waraporn., Sagnelli, Domenico., Meier, Sebastian., Jansson, Anita M., Lee, Byung-Hoo., Hamaker, Bruce R., RollandSabaté, Agnès., Hebelstrup, Kim H., Tongta, Sunanta., \& Blennow, Andreas., Structure of branching enzyme- and amylomaltase modified starch produced from well-defined amylose to amylopectin substrates.Carbohydrate Polymers http://dx.doi.org/10.1016/j.carbpol.2016.06.097

This is a PDF file of an unedited manuscript that has been accepted for publication. As a service to our customers we are providing this early version of the manuscript. The manuscript will undergo copyediting, typesetting, and review of the resulting proof before it is published in its final form. Please note that during the production process errors may be discovered which could affect the content, and all legal disclaimers that apply to the journal pertain. 


\section{Structure of branching enzyme- and amylomaltase modified starch produced from well-defined amylose to amylopectin substrates}

Waraporn Sorndech ${ }^{\mathrm{a}, \mathrm{b}}$, Domenico Sagnelli ${ }^{\mathrm{b}, \mathrm{h}}$, Sebastian Meier ${ }^{\mathrm{c}}$, Anita M. Jansson ${ }^{\mathrm{d}}$, Byung-Hoo

Lee $^{\mathrm{e}}$, Bruce R. Hamaker ${ }^{\mathrm{f}}$, Agnès Rolland-Sabaté ${ }^{\mathrm{g}}$, Kim H. Hebelstrup ${ }^{\mathrm{h}}$, Sunanta Tongta ${ }^{\mathrm{a}^{*}}$, Andreas Blennow ${ }^{b^{*}}$

\section{Affiliations}

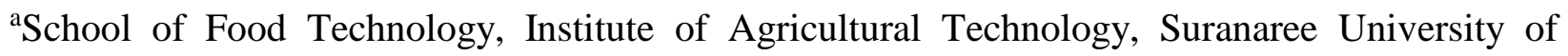
Technology, Nakhon Ratchasima 30000, Thailand

${ }^{b}$ Department of Plant and Environmental Sciences, Faculty of Sciences, University of Copenhagen, Frederiksberg C 1871, Denmark

${ }^{\mathrm{c}}$ Technical University of Denmark, Department of Chemistry, Kemitorvet, 2800 Kgs. Lyngby, Denmark

${ }^{\mathrm{d} C a r l s b e r g}$ Research Laboratory, Copenhagen V 1799, Denmark

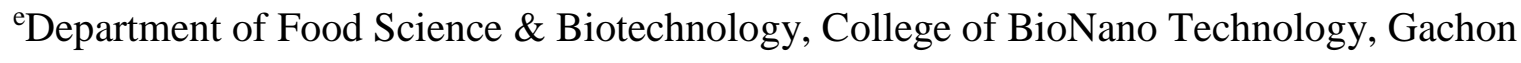
University, Seongnam 461-701, South Korea

fWhistler Center for Carbohydrate Research, Department of Food Science, Purdue University, Indiana 47907, United State of America

'UR126 8 Biopolymères Interactions Assemblages, INRA, F-44316 Nantes, France

${ }^{\text {h} D e p a r t m e n t ~ o f ~ M o l e c u l a r ~ B i o l o g y ~ a n d ~ G e n e t i c s, ~ A a r h u s ~ U n i v e r s i t y, ~ F o r s ø g s v e j ~ 1, ~} 4200$ Slagelse, Denmark 


\title{
Corresponding Authors
}

S. Tongta, School of Food Technology, Institute of Agricultural Technology, Suranaree University of Technology, Nakhon Ratchasima, Thailand. Tel: +66 44224266.

A. Blennow, Department of Plant and Environmental Sciences, Faculty of Sciences, University of Copenhagen, Copenhagen, Denmark Tel: +45 35333304

\section{Highlights}

- Enzyme modification of starch systems with well-defined amylose:amylopectin ratios provides detailed insight into the effects of substrate branching on enzymatic chain transfer

- $\quad$ High amylose substrates produce high branching rates, high $\overline{\mathrm{M}}_{\mathrm{w}}$, short chains and low amylolytic digestion when treated with branching enzyme alone or in combination with amylomaltase.

- Not only branching density but also molar mass of the glucan product restricts dietary degradation by steric hindrance towards human pancreatic $\alpha$-amylase and $\alpha$-glucosidases.

\begin{abstract}
Thermostable branching enzyme (BE, EC 2.4.1.18) from Rhodothermus obamensis in combination with amylomaltase (AM, EC 2.4.1.25) from Thermus thermophilus was used to modify starch structure exploring potentials to extensively increase the number of branch points
\end{abstract}


in starch. Amylose is an important constituent in starch and the effect of amylose on enzyme catalysis was investigated using amylose-only barley starch (AO) and waxy maize starch (WX) in well-defined ratios. All products were analysed for amylopectin chain length distribution, $\alpha$ 1,6 glucosidic linkages content, molar mass distribution and digestibility by using rat intestinal $\alpha$-glucosidases. For each enzyme treatment series, increased AO content resulted in a higher rate of $\alpha-1,6$ glucosidic linkage formation but as an effect of the very low initial branching of the AO, the final content of $\alpha-1,6$ glucosidic linkages was slightly lower as compared to the high amylopectin substrates. However, an increase specifically in short chains was produced at high AO levels. The molar mass distribution for the enzyme treated samples was lower as compared with substrate $\mathrm{WX}$ and $\mathrm{AO}$, indicating the presence of hydrolytic activity as well as cyclisation of the substrate. For all samples, increased amylose substrate showed decreased $\alpha$ - and $\beta$ amylolysis. Surprisingly, hydrolysis with rat intestinal $\alpha$-glucosidases was higher with increasing $\alpha-1,6$ glucosidic linkage content and decreasing $\bar{M}_{w}$ indicating that steric hindrance towards the $\alpha$-glucosidases was directed by the molar mass rather that the branching density of the glucan per se. Our data demonstrate that a higher amylose content in the substrate starch efficiently produces $\alpha-1,6$ glucosidic linkages and that the present of amylose generates a higher $\overline{\mathrm{M}}_{\mathrm{w}}$ and more resistant product than amylopectin. The combination of $\mathrm{BE} \rightarrow \mathrm{AM} \rightarrow \mathrm{BE}$ provided somewhat more resistant $\alpha$-glucan products as compared to BE alone.

Keywords: amylose content, branching enzyme, amylomaltase, starch degradation 


\section{Introduction}

The biosynthesis of starch and glycogen are complex processes consisting of a multitude of enzyme catalyzed transfer and hydrolysis reactions. In general, starch consists of two main components: amylose and amylopectin. Amylose is composed of long and mainly linear backbone $\alpha$-glucan chains linked together by $\alpha-1,4$ glucosidic linkages while amylopectin is a branched component linked together by $\alpha-1,4$ glucosidic backbone with $\alpha-1,6$ glucosidic branch points (Pérez and Bertoft, 2010). For the industry, such branching pattern is important and starches are selected and further modified to enhance its versatility and satisfy consumer demand (Tharanathan, 2005). Typically, increased branch density can increases solubility of the starch and can suppress amylolytic hydrolysis providing health-associated functionality (Sorndech et al., 2015). However, such glycogen-like functionality is not available in pure bulk quantity from starch crops.

Enzymatic modification of starch is gaining an interest as a clean and safe alternative to chemical modification (Blennow et al., 2013). Such enzymatic starch modification may be carried out either by the use of recombinant enzymes acting on purified starches, or alternatively the enzymes may be expressed directly in the starch producing crops by GM technology (Hebelstrup et al., 2015). However, the GM crop approach may sometimes modify the starch to an extend where its function as a storage of biomass and energy is jeopardized so that biological functions such as grain germination and seedling establishment are deficient (Shaik et al., 2014). Amylomaltase (AM, 4- $\alpha$-D- $\alpha$-glucanotransferase; E.C. 2.4.1.25. glucosyl hydrolase family 13 and 70, GH13 and GH70, www.CaZy.org) transfers $\alpha-1,4$ glucosidic linkages mainly within amylopectin and amylose, amylopectin cluster, or from amylose to amylopectin (Hansen, Blennow, Pedersen, Nørgaard and Engelsen, 2008). AM has been proven to add value to starch 
including its modification to impose gelatin-like functionality (Hansen et al., 2008) and increased degradative resistance (Jiang, Miao, Ye, Jiang and Zhang, 2014). Branching enzyme (BE, 1,4- $\alpha-$ D- $\alpha$-glucan:1,4- $\alpha$-D- $\alpha$-glucan $\quad 6-\alpha$-D-(1,4- $\alpha$-D- $\alpha$-glucano)-transferase, EC 2.4.1.18, glucosyl hydrolase family 13, GH13, www.CaZy.org) catalyses the formation of branch points in starch and glycogen biosynthesis by the cleavage of existing $\alpha-1,4$ glucosidic linkages followed by transfer to 1,6 hydroxyl groups to form the tree-like amylopectin and glycogen structures (Roussel et al., 2013; Shinohara et al., 2001). In vitro, BE also catalyses a cyclisation reaction to form cyclo-amylose and cylo-amylopectin cluster (Kelly, Dijkhuizen and Leemhuis, 2009; Takata et al., 1996). Starch modification with BE demonstrates an increase in solubility, reduced viscosity and for AM, increase degradative resistance of the product (Blennow et al., 2013). The thermostable BE from $R$. obamensis has drawn interest in starch modification to efficiently produce highly-branched $\alpha$-glucans (Roussel et al., 2013; Shinohara et al., 2001). Both amylose and amylopectin have been tested as substrate to identify possible different mechanisms. Some evidence suggests that $R$. obamensis BE activity was higher towards amylose than amylopectin (Shinohara et al., 2001). However, the substrate used was amylose from starch fractionation (Lee et al., 2008) which had amylopectin contamination or was enzymatic synthesized glucans containing DP 2-60 (Roussel et al., 2013), none of which the chain length was long enough compared to natural amylose. Different types of natural starch differ in their amylose content but there is only limited information on the effect of amylose on BE catalysed formation of $\alpha-1,6$ glucosidic linkages and cyclo-glucans (Andersson, Rydberg, Larsson, Andersson and Åman, 2002; Roussel et al., 2013; Takata et al., 1997; Takata, Takaha, Okada, Takagi and Imanaka, 1996). In a previous study, we modified cassava starch by using combinations of AM and BE to 
increase the content of $\alpha-1,6$ branch points. The results showed that the highest content of $\alpha-1,6$ branching points was achieved when using specific serial combinations of AM and BE.

In the present work we investigate the effects of amylose ratios of the substrate starch on $\mathrm{AM}$ and BE catalysis. As model substrates, we use the transgenic barley amylose-only (AO) starch which consists of more than $99 \%$ amylose (Carciofi et al., 2012) and 100\% amylopectin waxy (WX) maize starch in well-defined ratios. The efficiency of $\alpha-1,6$ branch formation for BE only and sequential $\mathrm{BE} \rightarrow \mathrm{AM} \rightarrow \mathrm{BE}$ treatment was investigated and the molecular structures and amylolytic digestibility analysed in vitro using rat intestinal $\alpha$-glucosidases. The study provides additional information to better understand how BE only and optimized combinations of BE and AM treatments affect the structure and digestibility of the enzyme-modified $\alpha$-glucan.

\section{Materials and methods}

\subsection{Materials}

Waxy maize starch (WX) was obtained from Cerestar-AKV I/S (Vodskov, Denmark). Amylose-only (AO) barley starch was obtained from Aarhus University (Aarhus, Denmark). BE, AM and $\beta$-glucanase were kindly provided from Novozymes (Bagsvaerd, Denmark). For BE and $\mathrm{AM}$, one $\mathrm{U}$ is defined as $1 \mu \mathrm{mole} / \mathrm{min}$ under standard conditions. Isoamylase (EC 3.2.1.68, specific activity $210 \mathrm{U} \cdot \mathrm{mL}^{-1}$ ) and $\beta$-amylase (EC 3.2.1.2, specific activity $620 \mathrm{U} \cdot \mathrm{mL}^{-1}$ ) was obtained from Megazyme (Wicklow, Ireland). Porcine pancreatic $\alpha$-amylase (EC 3.2.1.1, specific activity $22 \mathrm{U} \cdot \mathrm{mg}^{-1}$ ), and glucoamylase from Aspergillus niger (EC 3.2.1.3, specific activity $129 \mathrm{U} \cdot \mathrm{mg}^{-1}$ ) were purchased from Sigma-Aldrich (Missouri, USA). Proteinase K, recombinant, PCR grade was purchased from Roche (Hvidovre, Denmark). Enzyme activity units of isoamylase, $\alpha$-amylase and glucoamylase are given according to the supplier.

\subsection{AO barley starch extraction}


Amylose-only barley grains (Carciofi et al., 2012) were ground into fine powder and 200 $\mathrm{g}$ of flour were mixed in $2 \mathrm{~L}$ of $1 \mathrm{mM}$ DTT (dithiotreitol), and 1\% SDS (sodium dodecyl sulfate) for 30 min while stirring. The pellet was collected by sediment the starch granules on ice for 1-2 days. The washing procedure was repeated once. The pellet was resuspended in $2 \mathrm{~L}$ of deionized water and the slurry sieved through a $70 \mu \mathrm{m}$ sieve. To remove trace of cell-wall and protein contaminants, the granular starch preparation was subjected to $\beta$-glucanase and proteinase $\mathrm{K}$ treatments and the sedimented starch was washed 3 times in distilled water, once in $96 \%$ ethanol and finally air dried at room temperature.

\subsection{Non-granular AO starch preparation}

Non-granular starch was prepared according to Kong et al., (2008). Granular AO starch (5 g) was dissolved in $100 \mathrm{~mL}$ of $90 \%$ DMSO (dimethyl sulfoxide) by heating the mixture in a boiling water bath with constant stirring for $3 \mathrm{~h}$. The AO slurry was placed at room temperature and $200 \mathrm{~mL}$ of $95 \%$ ethanol was added with continuous stirring. A further $200 \mathrm{~mL}$ of $95 \%$ ethanol was added, the slurry was left at room temperature and then centrifuged at 2,500 $\times g$ for $10 \mathrm{~min}$. The precipitate was suspended with $25 \mathrm{~mL}$ of $95 \%$ ethanol and pelleted at $2,500 \times g$ for 10 min. The washing procedure was repeated once with $95 \%$ ethanol and finally with acetone. The final non-granular AO precipitate was freeze-dried (Kong, Bertoft, Bao and Corke, 2008).

\subsection{Enzymatic modification}

\subsubsection{BE action on substrates with well-defined amylose:amylopectin ratios}

BE-modified starch was produced mainly as described (van der Maarel et al., 2005) with slight modifications. The WX and AO mixtures $\left(2 \% \mathrm{w} \cdot \mathrm{v}^{-1}\right)$ with non-granular AO content varied from $0,20,50,80$ and $100 \%(0 \% \mathrm{AO}, 20 \% \mathrm{AO}, 50 \% \mathrm{AO}, 80 \% \mathrm{AO}$ and $100 \% \mathrm{AO})$ were suspended 
in $50 \mathrm{mM}$ phosphate buffer, $\mathrm{pH}$ 6.5. The suspension was heated to $120^{\circ} \mathrm{C}$ in an oil bath for $3 \mathrm{~h}$ while stirring by magnetic stirrer then cooled to $80{ }^{\circ} \mathrm{C}$ for $2 \mathrm{~min}$. BE $\left(4,000 \mathrm{U} \cdot \mathrm{g} \mathrm{starch}{ }^{-1}\right)$ was added to the gelatinised starch paste and incubated at $80{ }^{\circ} \mathrm{C}$ for $30 \mathrm{~min}$, then $60{ }^{\circ} \mathrm{C}$ for $24 \mathrm{~h}$. The reaction was terminated by heating in boiling water bath for $30 \mathrm{~min}$. The denatured protein and trace insolubles were removed by centrifugation $(1,500 \times \mathrm{g}$ for $20 \mathrm{~min})$. The supernatant containing the soluble $\alpha$-glucan product was recovered and dried at $50{ }^{\circ} \mathrm{C}$ overnight to less than $1 \%$ water content. The products were ground to a fine powder before further analysis.

\subsection{2 $\mathrm{BE} \rightarrow \mathrm{AM} \rightarrow \mathrm{BE}$ treatments with well-defined amylose:amylopectin substrate ratios}

A gelatinised starch paste was prepared as mentioned above, $\mathrm{pH}$ adjusted to 6.5 with 50 $\mathrm{mM}$ phosphate buffer, BE $\left(4,000 \mathrm{U} \cdot \mathrm{g} \operatorname{starch}^{-1}\right)$ was added and the mixture incubated at $60{ }^{\circ} \mathrm{C}$ for $24 \mathrm{~h}$. After termination of the reaction at $100{ }^{\circ} \mathrm{C}$ for $30 \mathrm{~min}, \mathrm{AM}\left(10 \mathrm{U} \cdot \mathrm{g} \mathrm{starch}{ }^{-1}\right)$ was added and incubation was performed at $\mathrm{pH} 6.0,70{ }^{\circ} \mathrm{C}$ for $3 \mathrm{~h}$. The reaction was terminated by boiling at 100 ${ }^{\circ} \mathrm{C}$ for $30 \mathrm{~min}$. In the last step, BE was added and incubation was performed under optimal conditions for $\mathrm{BE}$ as described above. The $\mathrm{BE}$ reaction was terminated and insoluble materials were removed by centrifugation and the product was dried as described in 2.4.1.

\section{$2.5 \beta$-amylolysis limit}

The $\beta$-amylolysis limit is the degree of hydrolysis of the $\alpha$-glucans by $\beta$-amylase which express as a percentage conversion of $\alpha$-glucans to maltose (Patil, 1976). The procedure was slightly modified from that of Wood and Mercier (1978). The $\alpha$-glucan solution $(1.5 \mathrm{~mL}, 0.5 \%$ $\mathrm{W} \cdot \mathrm{v}^{-1}$ in $\left.90 \% \mathrm{DMSO}\right)$ was mixed with an acetate buffer solution $\mathrm{pH} 4.8(0.3 \mathrm{~mL}, 0.2 \mathrm{M})$. The $\beta$ - 
amylase (4 units) and MilliQ water were added to a total volume of $2.7 \mathrm{~mL}$, the reaction mixture was vortexed and incubated at $37{ }^{\circ} \mathrm{C}$ for $48 \mathrm{~h}$. The reducing sugar content (Nelson, 1944) and total sugar content (Dubois, Gilles, Hamilton, Rebers and Smith, 1956) were measured. The percentage of $\beta$-amylolysis limit was calculated as follows (Wood and Mercier, 1978):

$\beta$-amylolysis limit $=\left(\frac{\text { Reducing sugar after hydrolysed-Reducing sugar of blank }}{\text { Total sugar after hydrolysed-Total sugar of blank }}\right) \times 100$

\subsection{Chain-length distribution of debranched $\alpha$-glucan}

The chain-length distribution of debranched $\alpha$-glucan samples were analysed by high performance anion-exchange chromatography coupled with pulsed amperometric detection (HPAEC-PAD). The $\alpha$-glucan samples were gelatinised by boiling and enzymatically debranched by using $0.24 \mathrm{U}$ of isoamylase per $5 \mathrm{mg}$ of sample at $40^{\circ} \mathrm{C}$. The obtained linear $\alpha$ glucan fragments were analysed by HPAEC-PAD (Dionex, Sunnyvale, CA, USA). Samples of $20 \mu \mathrm{L}(100 \mu \mathrm{g}$ of linear $\alpha$ - glucan) were injected on a CarboPac PA-200 column using 0.4 $\mathrm{mL} \cdot \mathrm{min}^{-1}$ flow rate, $150 \mathrm{mM}$ isocratic $\mathrm{NaOH}$ and the following $\mathrm{NaOAc}$ gradient profile: $0-5$ min: 0-110 mM linear gradient, 5-130 min: 110-350 mM convex gradient. Single peaks were integrated between DP 3-60 and corrected for the detector response (Viks $\varnothing-N i e l s e n$, Blennow, Nielsen and Møller, 1998). The average DP was calculated from the corrected values of the relative content of each chain.

\subsection{Molar mass distribution, hydrodynamic radius and dispersity analysis by size- exclusion chromatography with triple detection array (SEC-TDA)}

The weight-average molar mass distribution $\left(\bar{M}_{w}\right)$, the hydrodynamic radius $\left(R_{h}\right)$ and the dispersity $\left(\overline{\mathrm{M}}_{\mathrm{w}} / \overline{\mathrm{M}}_{\mathrm{n}}\right)$ were determined by size exclusion chromatography (SEC) using a Viscotek 
system (Malvern, UK) equipped with a GS-520 HQ column (Shodex, Showa Denko, Japan) attached to a TDA302 module (Triple detector array) consisting of a refractive index detector (RI), a four-bridge visco-meter detector (VIS) and a light scattering detector (LS). The LS consisted of a right angle light scattering (RALS) and a low angle light scattering (LALS). The calibration of the instrument was made using pullulan $\left(50,000 \mathrm{~g} \cdot \mathrm{mol}^{-1}\right.$, dispersity 1.07 , Showa Denko) as a standard which solubilised in MilliQ water $\left(1 \mathrm{mg} \cdot \mathrm{mL}^{-1}\right)$ and mixed at $99^{\circ} \mathrm{C}$ for 120 min at 1,000 rpm. Elution was carried out using $50 \mathrm{mM}$ ammonium formate $\left(\mathrm{HCO}_{2} \mathrm{NH}_{4}\right)$ buffer, $\mathrm{pH} 4.5$, at $0.5 \mathrm{~mL} \cdot \mathrm{min}^{-1}$ flow rate. Samples were filtered through a $0.22 \mu \mathrm{m}$ syringe filter and automatically injected (GPC max module) into the column. The injection volume was $50 \mu \mathrm{L}$ and the column temperature was $60^{\circ} \mathrm{C}$. The analysis was performed using the OmniSec Software 4.7 (Malvern Instrument, ltd.).

\subsection{Molar mass distribution, hydrodynamic radius and dispersity analysis by asymmetrical flow field-flow fractionation coupled with multiangle laser light scattering (AF4-MALLS)}

AF4-MALLS was used to study high molecular and shearing-sensitive samples like unmodified starch. AO were dissolved in 95\% DMSO, precipitated with ethanol and dried (Bello-Pérez, Colonna, Roger and Octavio, 1998; Rolland-Sabaté, Guilois, Jaillais and Colonna, 2011). WX was solubilised in water by microwave heating under pressure (Bello-Pérez et al., 1998; Rolland-Sabaté et al., 2011) and filtered (5 $\mu \mathrm{m})$. AO starch was directly solubilised at a concentration of $10 \mathrm{mg} \cdot \mathrm{mL}^{-1}$ in $1 \mathrm{M} \mathrm{KOH}$, for $2 \mathrm{~h}$ at $4{ }^{\circ} \mathrm{C}$. The solution was diluted ten times with water and filtered through a $0.45 \mu \mathrm{m}$ membrane filter. Solubilisation recoveries were calculated by comparing carbohydrate concentrations after and before filtration (Rolland-Sabaté et al., 2011). Aliquots (50 $\mu \mathrm{L}$ and $100 \mu \mathrm{L})$ were injected on to the AF4-MALLS instrument 
using an autosampler WPS-3000SL (Thermo Scientific, Waltham, USA). The equipment included a long AF4 channel, a ThermosPRO oven thermostated at $25^{\circ} \mathrm{C}$, and Eclipse to control the flows in the channel (Wyatt Technology Corporation, Santa Barbara, USA). The channel geometry was trapezoidal with a tip-to-tip length of $291 \mathrm{~mm}$. A $350 \mu \mathrm{m}$ polyester spacer and a regenerated cellulose membrane with a cutoff of $10,000 \mathrm{~g} \cdot \mathrm{mol}^{-1}$ was from Merck Millipore (Darmstadt, Germany). The two on-line detectors comprised a MALLS instrument (Dawn® HELEOS $\left.^{\mathrm{TM}}\right)$ fitted with a $\mathrm{K} 5$ flow cell and a He-Ne laser $(\lambda=658 \mathrm{~nm})$ and an Optilab refractometer operating at the same wavelength (Wyatt Technology Corporation, Santa Barbara, CA). The carrier (Millipore water containing $0.2 \mathrm{~g} \cdot \mathrm{L}^{-1}$ sodium azide) was filtered through $0.1 \mu \mathrm{m}$ and degassed. Starches were eluted with the flow method described in Rolland-Sabaté et al. (2011). Elution recovery rates were calculated from the ratio of the mass eluted from the channel and the injected mass. $\overline{\mathrm{M}}_{\mathrm{w}}, \mathrm{R}_{\mathrm{h}}$ and dispersity $\left(\overline{\mathrm{M}}_{\mathrm{w}} / \overline{\mathrm{M}}_{\mathrm{n}}\right)$ were calculated using ASTRA ${ }^{\circledR}$ software from WTC (version 6.1.2.84 for PC). A value of $0.146 \mathrm{~mL} \cdot \mathrm{g}^{-1}$ was used as the refractive index increment $(\mathrm{dn} / \mathrm{dc})$ for glucans.

\subsection{Determination of $\alpha-1,6$ glucosidic linkages by ${ }^{1} \mathrm{H}$-nuclear magnetic resonance spectroscopy ( $\left.{ }^{1} \mathrm{H}-\mathrm{NMR}\right)$}

$\alpha$-Glucan samples $\left(0.3 \% \mathrm{~W} \cdot \mathrm{v}^{-1}\right)$ were prepared in $500 \mu \mathrm{L} \mathrm{D} \mathrm{D}_{2} \mathrm{O}$ (Cambridge Isotope Laboratories, Andover, MA, USA) under gentle heating. Bruker (Fällanden, Switzerland) DRX spectrometer equipped with a TCI CryoProbe and an $18.7 \mathrm{~T}$ magnet (Oxford Magnet Technology, Oxford, UK) were used to record the ${ }^{1} \mathrm{H}-\mathrm{NMR}$ spectra at $37{ }^{\circ} \mathrm{C}$. Spectra were recorded by sampling 16,384 complex data points during an acquisition time of $1.7 \mathrm{sec}$, employing 32 transients and a recycle delay of $10 \mathrm{sec}$ for reliable quantifications. Bruker 
Topspin 2.1 software with zero filling in all dimensions and mild resolution enhancement were used to process NMR spectra.

\subsection{Matrix assisted laser desorption ionization-time of flight mass spectrometry (MALDI-TOF MS)}

MALDI-TOF MS were used to validate cyclo-structures of the samples. The matrix was $20 \mathrm{mg} \cdot \mathrm{mL}^{-1}$ of 2,5-dihydroxybenzoic acid in $30 \%$ acetonitrile in water with $0.1 \%$ TFA. The $\alpha$ glucan samples were dissolved in DMSO and diluted with water to a final concentration of 1

$\mu \mathrm{g} \cdot \mathrm{mL}^{-1}$. The diluted analyte solution $(2 \mu \mathrm{L})$ was combined with the matrix solution $(2 \mu \mathrm{L})$ and this solution $(0.5 \mu \mathrm{L})$ was added to the target and air-dried. MALDI-TOF MS was performed on a Bruker Daltonics Microflex instrument operating in reflectron mode. A $340 \mathrm{~nm}$ laser was used and mass spectra were typically accumulated from 1,000 laser shots. Spectra were generally acquired over a $4,000 \mathrm{~m} / \mathrm{z}$ range.

\subsection{Hydrolysis properties by human pancreatic $\alpha$-amylase}

Human pancreatic $\alpha$-amylase hydrolytic degradability of the $\alpha$-glucan samples was investigated following solubilisation of the $\alpha$-glucan $\left(10 \mathrm{mg} \cdot \mathrm{mL}^{-1}\right)$ in $10 \mathrm{mM}$ PBS buffer (pH 6.9) by boiling for $20 \mathrm{~min}$. After cooling, an aliquot of the sample (1 mL) was incubated with $500 \mathrm{U}$ human pancreatic $\alpha$-amylase (Meridian Life Science, Inc., Saco, Maine) at $37{ }^{\circ} \mathrm{C}$ for $24 \mathrm{~h}$ with mixing. The reaction was terminated by boiling for $20 \mathrm{~min}$. The hydrolysed samples containing $\alpha$-limit dextrins were analysed for their apparent molar mass by HPSEC-RI (Zhang, Ao and Hamaker, 2006) using pullulans as standard (Polymer Laboratories Inc. Amherst, MA).

2.12 Determination of glucose release from modified $\alpha$-glucan samples by rat intestinal $\alpha$-glucosidases 
Rat intestinal acetone powder containing $\alpha$-glucosidase (Sigma-Aldrich Co., St. Louis, MO) was mixed with $20 \mathrm{~mL}$ of sodium phosphate buffer $(100 \mathrm{mM}, \mathrm{pH} 6.8)$ and solubilized by incubation at $4^{\circ} \mathrm{C}$ for $24 \mathrm{~h}$. An aliquot of the $\alpha$-limit dextrins $(200 \mu \mathrm{L})$ was further incubated at $37{ }^{\circ} \mathrm{C}$ with the rat intestinal $\alpha$-glucosidase $(500 \mathrm{U}$, one unit (U) enzyme activity arbitrarily defined as $1 \mu \mathrm{g}$ of glucose released from $1 \%$ maltose per $10 \mathrm{~min}$ at $37^{\circ} \mathrm{C}$ ). The mixture was centrifuged at $8,000 \mathrm{rpm}$ for $15 \mathrm{~min}$, and the supernatant was filtered through a $0.8 \mu \mathrm{m}$ nylon membrane. The amount of released glucose at 240 min was determined by the glucose oxidase/peroxidase (GOPOD) method (Vasanthan, 2001) and expressed as percentage of the starting material weight as described in 2.11 .

\section{Results and discussions}

\section{$3.1 \alpha-1,6$ glucosidic linkages}

Mixtures of well-defined amylose:amylopectin ratios ranging 0, 20, 40, 60, 10 and 100\% amylose generated by mixing $\mathrm{AO}$ and $\mathrm{WX}$ starches were treated with BE separately and AM and/or $\mathrm{BE}$ in sequential steps $(\mathrm{BE} \rightarrow \mathrm{AM} \rightarrow \mathrm{BE})$ (Table 1). The $\alpha-1,6$ linkage contents of substrates and products as determined by ${ }^{1} \mathrm{H}-\mathrm{NMR}$ (Table 1, original spectra shown in Supplementary Fig. 1) showed that the modified starches had a higher content of $\alpha-1,6$ linkages ranging 7.0-8.7 \% for BE-treated starch and 8.0-9.7 \% for $\mathrm{BE} \rightarrow \mathrm{AM} \rightarrow \mathrm{BE}-$ treated starch compared to the original AO $(0.2 \%)$ and WX $(3.5 \%)$ substrates. For each enzyme treatment series, a more AO content resulted in a higher rate of $\alpha-1,6$ linkage formation (Table 1). An increase in $\alpha-1,6$ linkage formation for the $0 \%$ AO sample treated with BE was 1.5-fold while the $100 \%$ AO sample showed a 34.0-fold increase as compared to the original substrates (Table 1). These results are in agreement with those obtained by Shinohara et al. (2001) who suggested that $R$. obamensis BE has a six-fold higher activity for amylose than for amylopectin. However, 
another study (Roussel et al., 2013), using synthetic amylose DP 2-60 as a substrate for $R$. obamensis, BE showed that BE preferentially used branched substrates as acceptors. Our data provides a possible explanation for this apparent discrepancy in that BE preferably uses the slightly branched AO chain segments as both donors and acceptors substrates. The BE activity on the WX starch was possibly limited by branching steric hindrance and we suppose that new branch points in the $0 \% \mathrm{AO}$ sample might be mainly located on the outer chains of glucan structure and a higher $\mathrm{AO}$ ratios in $\mathrm{AO}: \mathrm{WX}$ mixture provides a more optimal donor substrate for BE to create new branch points.

The $\mathrm{BE} \rightarrow \mathrm{AM} \rightarrow \mathrm{BE}$ modified starches showed a higher content of $\alpha-1,6$ linkages as compared to the BE only (Table 1). This is in agreement with our previous study using cassava starch as substrate (Sorndech et al., 2015). An increase in $\alpha-1,6$ linkages for the $0 \%$ AO (only WX, amylopectin) treated sequentially with $\mathrm{BE} \rightarrow \mathrm{AM} \rightarrow \mathrm{BE}$ was 1.8 -fold as compared to the WX substrate while the $100 \%$ AO showed a 39.0-fold increase. These increments are slightly higher than the BE only catalyzed branching described above and demonstrates that AM provides a more efficient substrate for BE to slightly further increase the degree of branching by its disproportion activity. It should be noted that as an effect of the very low initial branching of the AO starch, the final content of $\alpha-1,6$ linkages was slightly lower with increasing AO content (Table 1). Both $\mathrm{BE}$ and $\mathrm{BE} \rightarrow \mathrm{AM} \rightarrow \mathrm{BE}$ treated glucans showed that a higher $\mathrm{AO}$ content resulted in the more $\alpha$-glucose monomers or reducing end groups. Support for such a minor hydrolytic activity was provided by ${ }^{1} \mathrm{H}$-NMR data of anomeric hydrogens in $\alpha$-glucose monomers or end group located at $5.30 \mathrm{ppm}$ (Supplementary Fig. 1). The presence of these segments may be a consequence during transfer activity leaving the un-attached glucan chains. 


\subsection{Chain-length distribution}

The native and the modified $\alpha$-glucan products were debranched using excess isoamylase in order to determine the chain length distribution profiles between DP 3-65 by HPAEC-PAD. The unit chain distribution can be classified into A-chains (DP 6-12), B1-chains (DP 13-24), B2chains (DP 25-36) and long B3-chains (DP > 37) (Hanashiro, Abe \& Hizukuri, 1996). The BE and $\mathrm{BE} \rightarrow \mathrm{AM} \rightarrow \mathrm{BE}$ modified starches had higher number of short chains of approximately DP 312, corresponding to A-chains, as compared to AO and WX substrates (Fig. 1A, Table 2). It should be noted that, for the AO starch, the total PAD detection for the chains between DP 3-65 only constituted $8 \%$ of the control starch, supporting the low degree of branching of this sample, i.e. more than $92 \%$ of $\mathrm{AO}$ chains were very long, $\mathrm{DP} \geq 65$. SEC data of this starch (Carciofi et al., 2012) substantiates that $99 \%$ of the material in this starch has amylose-like structure. For the BE modified starches, the depletion in the chains of DP > 12 (Table 2) suggests the consumption of B1, B2 and long chains, which were used as donor substrates to produce new branch points by BE creating the A-chains. The long chains (mainly B3-chains) were virtually absent after enzyme modification suggesting a complete consumption of B3 chains. Especially, for the 0\% AO starch treated only with $\mathrm{BE}$, the DP 3-13 chains were abundant after debranching while chains of DP $\geq 14$ were decreased (Fig. 1D). However, for the $100 \%$ AO starch treated the same, this decrease affected the slightly longer chains ( $D P \geq 17$, Fig. 1D). This difference, though minor, may explain the relatively good correlation between the increased $\mathrm{AO}$ and the maximum length of donor substrate chains, which increased from DP 13 for the 0\% AO substrate to DP 16 for the $100 \% \mathrm{AO}$ substrate. These results suggested that $\mathrm{BE}$ prefers long chain glucans present in amylose as donor substrate (Fig. 3C). However, a minor part of the DP 3-12 chain pool was already present in the modified $\alpha$-glucans before debranching (data not shown). The amount of 
these chains was increased with the more AO substrate content supporting that BE prefers to use $\mathrm{AO}$ as a donor substrate for the branching reaction cleaving off donor residual segments until the chains were too short to accommodate in the BE catalytic subsites. As deduced from our data, the optimal chain length for BE substrate binding was DP 16 and for chain transfer DP 6-7 from the non-reducing end (Fig. 1D). These results are in agreement with previous investigations (Kittisuban, Lee, Suphantharika and Hamaker, 2014; Roussel et al., 2013) using R. obamensis $\mathrm{BE}$ with selected types of starches as substrate. Interestingly, the chains in the $\mathrm{BE} \rightarrow \mathrm{AM} \rightarrow \mathrm{BE}$ modified starches clearly showed a distributional trend characterized by an increase in short chains of DP 3-12 with higher AO substrate content (Fig. 1C). For the debranched products produced from the $0 \%$ AO substrate treated with BE, the DP 3-12 chain pools were dramatically increased while chains DP $\geq 12$ were lower (Fig. 1E). For the corresponding $100 \%$ AO substrate this decrease occurred at somewhat longer chains i.e., DP $\geq 15$ (Fig. 1C and 1E). The $\mathrm{BE} \rightarrow \mathrm{AM} \rightarrow \mathrm{BE}$ treated starch showed a shorter optimum donor chain length (DP 15) compared to the BE-treated starch mixtures (DP 17), indicating an efficient AM catalysis on AO. The dominant binding mode of AM from Thermus thermophilus (Kaper et al., 2007) indicates the transfer of chains at least DP 3 long. Thus, as compared to the BE only treated starch, the optimum donor chains for BE was presumably consumed after BE $\rightarrow$ AM treatment resulting the presence of shorter transferred glucan chains by BE in the last step. These results differ from data for Bacillus sp. BE for which the optimum donor chain length is considerably shorter i.e. DP 12 (Kiel, Boels, Beldman and Venema, 1991).

The apparent non-coherence with the amount of $\alpha-1,6$ linkages analysed by NMR and the high amount of short chains at approximately DP 3-15 (Table 1 and Fig. 1) after enzyme treatment, can be attributed to minor hydrolysis exerted by the transferases. However, already for 
non-debranched samples we observed an increase in short chains (approximately DP 3-8) with higher AO:WX ratios. For the debranched samples, DP 6 was the smallest branch side chains created by BE (not shown), however, only in minute amounts. Some long chains may have been lost following gelatinization of the $\mathrm{AO}$ and subsequent cooling and aggregation. Such a fraction would not be resolved by HPAEC-PAD but can contribute to the $\alpha-1,4$ linkages content in the NMR signal.

\subsection{Molar mass distribution, hydrodynamic radius, dispersity, intrinsic viscosity and cyclo-structures formation}

The molar mass distribution $\left(\bar{M}_{w}\right)$, hydrodynamic radius $\left(R_{h}\right)$ and dispersity $\left(\bar{M}_{w} / \bar{M}_{n}\right)$ of the enzyme-modified starches were determined by SEC-TDA. The $\overline{\mathrm{M}}_{\mathrm{w}}$ of AO and WX starch substrates were determined by AF4-MALLS as summarized in Table 3. The $\overline{\mathrm{M}}_{\mathrm{w}}$ of WX was $3.99 \times 10^{8} \mathrm{~g} \cdot \mathrm{mol}^{-1}$ while for AO was $5.50 \times 10^{6} \mathrm{~g} \cdot \mathrm{mol}^{-1}$. All BE and BE $\rightarrow \mathrm{AM} \rightarrow \mathrm{BE}$ treated starches had lower $\overline{\mathrm{M}}_{\mathrm{w}}$ as compared to the non-modified WX and AO. This indicates that, during the transfer reaction, hydrolysis is also taking place and/or highly branched-amylopectin clusters were produced (Table 3, Fig. 3A). The low viscometer signal for the enzyme-treated samples did not provide reliable viscosity $[\eta]$ data and was therefore not employed for calculations using the Mark-Houwink equation $\left([\eta]=\mathrm{KMw}^{\alpha}\right.$, where $\mathrm{K}$ and $\alpha$ are the Mark-Houwink constants). However, a log-log plot of Rh vs molar mass estimated rod-like shape of the products. The low product viscosity supports the cyclisation and minor hydrolytic activities producing small compact, highly branched and cluster-like products. The resulting products derived from the $0 \%$ AO substrate for both enzyme-treatments showed higher molecular density compared to that of $100 \%$ AO substrate indicating variation of molecular conformation of the resulting products 
(Fig. 3A-E). Comparative analysis of synthetic amylose of DP 2-60 and potato amylopectin as a substrates $R$. obamensis $\mathrm{BE}$ showed that the potato amylopectin was a better acceptor substrate than the synthetic amylose and those chains larger than DP 11 were optimal donor chain lengths (Roussel et al., 2013). This is in accordance with our data since BE had high activity towards slightly branched and long-chain glucans represented by the AO starch. Minor low molar mass peaks were also observed for the higher AO:WX ratio substrates before the end of the SEC-TDA chromatogram (not shown) indicating various species of molecules generated during enzyme catalysis when using high amylose substrate. The reduction of $\overline{\mathrm{M}}_{\mathrm{w}}$ following BE treatment has been reported elsewhere (Kim, Ryu, Bae, Huong and Lee, 2008; Le et al., 2009). However, an important effect observed for both $\mathrm{BE}$ and $\mathrm{BE} \rightarrow \mathrm{AM} \rightarrow \mathrm{BE}$ treated starches was an increase in molar mass of the product with increasing AO:WX substrate ratio (Table 3). Supposedly, this effect is due to the high specificity of $\mathrm{BE}$ preferably using $\mathrm{AO}$ for both donor and acceptor chains as discussed above. The presence of steric hindrance in the WX structure may prevent BE to penetrate the branched structure to access and catalytically act on the acceptor chains during the transfer reaction compared to the more linear $\mathrm{AO}$ acceptor chains.

The possible production of small cyclodextrins was tested by MALDI-TOF (Supplementary Fig. 2). The smallest cyclic $\alpha$-glucan found was $\gamma$-cyclodextrin (DP8, m/z 1,320) and it was detected in all modified starches, especially the AM treated samples. A decrease in $\overline{\mathrm{M}}_{\mathrm{w}}$ for all the products indicates the production of cyclostructures with varying $\overline{\mathrm{M}}_{\mathrm{w}}$ including cyclo-amylose (Fig. 3D) and cyclo-amylopectin clusters (Fig. 3B). Thus, a decrease in $\overline{\mathrm{M}}_{\mathrm{w}}$ with decreasing $\mathrm{AO}$ ratio is supposedly mainly due to the production of cyclo-amylopectin clusters. However, the high melting point of the AO starch should also be considered. Thermal analysis by differential scanning calorimetry (DSC) of AO revealed that it gelatinised above $100{ }^{\circ} \mathrm{C}$ 
(Carciofi et al., 2012). Eventhough the AO starch was fully gelatinised prior to the following enzyme treatment at $60{ }^{\circ} \mathrm{C}$, minor aggregation might occur after cooling and during the transfer reactions (Fig. 3E). The $\overline{\mathrm{M}}_{\mathrm{w}} / \overline{\mathrm{M}}_{\mathrm{n}}$ ranged 1.4-2.9 for the products demonstrating some degree of dispersity. However, the high $\overline{\mathrm{M}}_{\mathrm{w}} / \overline{\mathrm{M}}_{\mathrm{n}}$ value (6.2) of the AO substrate was extensively reduced by enzyme treatment. Hence, the reduction in $\bar{M}_{w}$ following AM and/or BE catalysis is likely a combined effect of hydrolysis and the formation of amylopectin cluster and cyclic $\alpha$-glucan. However, the monodispersity of the products suggests that the hydrolytic reaction was very minor.

\section{4 $\alpha$-limit dextrin structure and $\beta$-amylolysis limit}

The content of $\alpha$-limit dextrin and $\beta$-amylolysis limit were determined in order to elucidate their molecular structure. The $\alpha$-limit dextrin content was determined by HPSEC-RI while the $\beta$-amylolysis limit was determined by reducing end analysis (Nelson, 1944). The increased branching of the $\mathrm{BE}$ and $\mathrm{AM}$ treated products increased the production of $\alpha$-limit dextrins as compared to the corresponding AO and WX substrates (Table 4). However, the $\beta$ amylolysis limit decreased with the same treatments demonstrating that the products after BE and AM treatment had lower $\beta$-amylase susceptibility than the starch substrate. All BE and $\mathrm{BE} \rightarrow \mathrm{AM} \rightarrow \mathrm{BE}$ treated starches produced smaller amounts of $\alpha$-limit dextrin and lower $\beta$ amylolysis limit at higher AO:WX ratios. The decrease in $\alpha$-limit dextrin was similar for both treatments. The BE-treated samples showed ranging from $32.3 \%$ to $6.5 \%$ as for the $\mathrm{BE} \rightarrow \mathrm{AM} \rightarrow \mathrm{BE}-$ treated samples (from $34.5 \%$ to $7.3 \%$, Table 4, Fig. 2). This trend demonstrates that less branched structures were obtained as AO increased which is associated with the branch linkage analysis (Table 1). The action pattern of $\alpha$-amylase involves a virtually random 
hydrolytic multiple attack to cleave starch into linear and branched dextrins (Bijttebier, Goesaert and Delcour, 2008) and requires at least a four glucose-unit linear segment between two branch points for catalysis (Damager et al., 2005). The low $\alpha$-limit dextrin content of the samples having low branch point density is in accordance with the specific action of $\alpha$-amylase on linear a-1,4 chains. A previous study (Kandra, Gyémánt, Remenyik, Hovánszki and Lipták, 2002) demonstrated that the maximum frequency of $\alpha$-amylase attack site is shifted towards the reducing end with longer chain length. Therefore, our data do not exclude that the distance between each branch points in the products were shorter or equal to four glucose units (Fig. 3C).

The $\beta$-amylase degradation of BE-treated samples was increased from $20.0 \%$ to $33.3 \%$ with increasing AO substrate. This implies that BE preferentially uses AO, initially creating new branch points expected to be located mostly on the non-reducing end of the $\alpha$-glucan acceptor chains where $\beta$-amylase is less active (Fig. $3 \mathrm{C}$ ). In addition, the $\beta$-amylolysis limit from BEtreated samples was higher than that of the $\mathrm{BE} \rightarrow \mathrm{AM} \rightarrow \mathrm{BE}$-treated samples which decreased from $21.4 \%$ to $12.2 \%$ with increasing $\mathrm{AO}$ (Table 4). This result confirms that the disproportionation activity of $\mathrm{AM}$ in the $\mathrm{BE} \rightarrow \mathrm{AM} \rightarrow \mathrm{BE}$-treated samples promotes the production of more complex structures as compared to the BE-treated samples. Such branch structures are more $\beta$-amylase resistant than randomly branched glucans. The combine results of $\alpha$-limit dextrin content and $\beta$-amylolysis limit provides evidence that the product following $\mathrm{BE}$ chain transfer in high amylose:amylopectin systems causes longer distance between the adjacent branch point in the product. The new branch points were located mostly on the non-reducing end of the acceptor $\alpha$-glucan chains. 


\subsection{Glucose released after rat intestinal $\alpha$-glucosidases hydrolysis}

In order to investigate the internal branch structure of the $\alpha$-limit dextrins (Fig. 2) obtained from the enzyme modified starches, the samples were subjected to further hydrolysis by rat intestinal $\alpha$-glucosidases after hydrolysis by human pancreatic $\alpha$-amylase. These data would also indicate the potential degradative pattern of the $\alpha$-limit dextrins in the intestinal part of gastrointestinal tract. These amylases consist of maltase-glucoamylase (MGAM) and sucraseisomaltase (SI) and they are mainly active on $\alpha-1,4$ and $\alpha-1,6$ linkages, respectively (Lin et al., 2012). Hydrolysis of $\alpha$-limit dextrin is expected to specifically slow down the MGAM and SI activities due to the highly-branched structures of these glucans (Lee et al., 2013). Glucose released from all $\mathrm{BE}$ and $\mathrm{BE} \rightarrow \mathrm{AM} \rightarrow \mathrm{BE}$ treated starches after hydrolysis by human pancreatic $\alpha-$ amylase and rat intestinal $\alpha$-glucosidases were 43.0-58.0 \% and 38.0-51.0 \%, respectively, with decreasing AO:WX ratios (Table 5). A positive relationship was found between the amount of branched $\alpha$-limit dextrins in the hydrolysis product and the amount of glucose generated. The $\alpha-$ limit dextrins obtained from the $\mathrm{BE} \rightarrow \mathrm{AM} \rightarrow \mathrm{BE}$ treated starches released lower glucose as compared to the $\mathrm{BE}$ treated starches. This result demonstrates an effect of $\mathrm{AM}$ on arrangement the $\alpha$-glucan structure due to it disproportionation activity of the $\alpha$-glucan linear chains or clusters. In addition, a previous study demonstrated that $\alpha$-glucan hydrolysis rate by MGAM-SI is low on densely branched $\alpha$-limit dextrin (Kittisuban et al., 2014; Lee et al., 2013). Particular chemical structures including tightly branched clustered in the $\alpha$-limit dextrin can affect the MGAM-SI catalysis (Lin et al., 2010).

The samples after $\mathrm{BE}$ and $\mathrm{BE} \rightarrow \mathrm{AM} \rightarrow \mathrm{BE}$ treatment were analysed by HPAEC-PAD in order to investigate the formation of isomaltose, isomaltotriose and highly branched oligosaccharides. All of them are slowly digested by isomaltase in human body (Gropper, Smith 
and Groff, 2009). Only low amounts of isomaltose and isomaltotriose were detected (data not shown). This finding indicates that the fraction denoted as "linear" found in the HPSEC-RI chromatograms possibly consisted of both isomaltose and isomaltotriose and were hence slowly digested. The MGAM has a preference for short $\alpha-1,4$ linkages while SI has a broader specificity for both $\alpha-1,4$ and $\alpha-1,6$ linkages (Sim et al., 2010). The 100\% AO product might contain long chains with highly branch points, and some of them might be in a form of double helical segments which can resist MGAM-SI hydrolysis. Our results are in agreement with those of Ao et al., 2007 who proposed that the slowly digested and resistant properties of the enzymemodified starch were not affected only from the higher content of $\alpha-1,6$ linkages and shortened chains. It was also likely to be a minor effect from short amylose fragments that were selfassociated which reduced enzyme hydrolysis. The propose products generated from BE and $\mathrm{BE} \rightarrow \mathrm{AM} \rightarrow \mathrm{BE}$ on WX and $\mathrm{AO}$ substrate were represented in Fig. 3A-E.

\section{Conclusions}

$\mathrm{BE}$ more efficiently catalyzed chain transfer in $\mathrm{AO}$ than WX to create new branch points and to produce a low and more monodisperse product. The BE- and BE $\rightarrow \mathrm{AM} \rightarrow \mathrm{BE}-$ treated starches showed an higher rate of $\alpha-1,6$ glucosidic linkages formation and short chains approximately DP 3-16 with higher AO:WX ratios. However, due to a very low initial branch content of the AO starch, the final content of $\alpha-1,6$ glucosidic linkages was slightly lower at high AO substrate content. Sequential $\mathrm{BE} \rightarrow \mathrm{AM} \rightarrow \mathrm{BE}$ catalysis resulted in more extensive branching as compared to using BE alone. This increased branching suppressed amylolytic susceptibility as demonstrated by increased levels of $\alpha$-limit dextrins for each of the substrates. However, high amylose substrates generated lower level of $\alpha$-limit dextrin demonstrating that amylose substrate 
generated less $\alpha$-amylase resistant products. Further hydrolysis with rat intestinal $\alpha$-glucosidases showed increased hydrolysis rate with higher $\alpha-1,6$ glucosidic linkage content and decreased molar mass. This suggests that $\alpha$-glucosidases is sterically hindered by the molar mass and molecular configuration rather that the branching density of the glucans per se. Combined $\mathrm{BE} \rightarrow \mathrm{AM} \rightarrow \mathrm{BE}$ produced more resistant $\alpha$-glucan products as compared to BE alone. Overall, the high amylose starch shows a better potential source to be applied as a raw material for enzymatic modification to produce slowly- and resistant dextrin.

\section{Acknowledgements}

This research was supported by The Thailand Research Fund (The Royal Golden Jubilee Ph.D. Program for Industry, Grant no. PHD/0129/2553) and Suranaree Univeristy of Technology (SUT) and by the Office of the Higher Education Commission under NRU Project of Thailand. NMR spectra were recorded at the $800 \mathrm{MHz}$ spectrometer of the Danish National Instrument Center for NMR spectroscopy of Biological Macromolecules at the Carlsberg Laboratory. The Viscotek-TDA was provided by a grant from the Carlsberg Foundation. Novozymes A/S is acknowledged for providing AM and BE.

\section{References}

Ao, Z., Simsek, S., Zhang, G., Venkatachalam, M., Reuhs, B. L., \& Hamaker, B. R. (2007). Starch with a slow digestion property produced by altering its chain length, branch density, and crystalline structure. Journal of Agricultural and Food Chemistry, 55(11), 4540-4547.

Andersson, L., Rydberg, U., Larsson, H., Andersson, R., \& Åman, P. (2002). Preparation and 
characterisation of linear dextrins and their use as substrates in in vitro studies of starch branching enzymes. Carbohydrate Polymers, 47(1), 53-58.

Bailey, J. M., \& Whelan, W. J. (1957). The mechanism of carbohydrase action. 3. The action pattern of $\beta$-amylase. Biochemical Journal, 67(4), 540-547.

Bello-Pérez, L. A., Colonna, P., Roger, P., \& Octavio, P.-L. (1998). Laser light scattering of high amylose and high amylopectin materials in aqueous solution, effect of storage time. Carbohydrate Polymers, 37(4), 383-394.

Bijttebier, A., Goesaert, H., \& Delcour, J. (2008). Amylase action pattern on starch polymers. Biologia, 63(6), 989-999.

Blennow, A., Jensen, S. L., Shaik, S. S., Skryhan, K., Carciofi, M., Holm, P. B., et al. (2013). Future cereal starch bioengineering: Cereal ancestors encounter gene technology and designer enzymes. Cereal Chemistry, 90(4), 274-287.

Carciofi, M., Blennow, A., Jensen, S., Shaik, S., Henriksen, A., Buleon, A., et al. (2012).

Concerted suppression of all starch branching enzyme genes in barley produces amyloseonly starch granules. BMC Plant Biology, 12(1), 223.

Damager, I., Jensen, M.T., Olsen, C.-E., Blennow, A., Møller, B.L., Svensson, B., et al. (2005) Chemical synthesis of a dual branched malto-decasaccharide investigated as potential substrate for $\alpha$-amylases. ChemBioChem, $6,1224-1233$.

Dubois, M., Gilles, K. A., Hamilton, J. K., Rebers, P. A., \& Smith, F. (1956). Colorimetric method for determination of sugars and related substances. Analytical Chemistry, 28(3), $350-356$.

Gropper, S. S., Smith, J. L., \& Groff, J. L. (2009). Advanced Nutrition and Human Metabolism (5 ed.). Canada: Cengage learning. 
Hanashiro, J., Abe, J., \& Hizukuri, S. (1996). A periodic distribution of the chain length of amylopectin as revealed by high-performance anion-exchange chromatography. Carbohydrate Research, 283, 151-159.

Hansen, M. R., Blennow, A., Pedersen, S., Nørgaard, L., \& Engelsen, S. B. (2008). Gel texture and chain structure of amylomaltase-modified starches compared to gelatin. Food Hydrocolloids, 22(8), 1551-1566.

Hebelstrup, K. H., Sagnelli, D., \& Blennow, A. (2015). The future of starch bioengineering: GM microorganisms or GM plants? Frontiers in Plant Science, 6: 247.

Jiang, H., Miao, M., Ye, F., Jiang, B., \& Zhang, T. (2014). Enzymatic modification of corn starch with 4- $\alpha$-glucanotransferase results in increasing slow digestible and resistant starch. International Journal of Biological Macromolecules, 65(0), 208-214.

Kandra, L., Gyémánt, G., Remenyik, J., Hovánszki, G., \& Lipták, A. (2002). Action pattern and subsite mapping of Bacillus licheniformis $\alpha$-amylase (BLA) with modified maltooligosaccharide substrates. FEBS Letters, 518(1-3), 79-82.

Kaper, T., Leemhuis, H., Uitdehaag, J. C. M., van der Veen, B. A., Dijkstra, B. W., van der Maarel, M. J. E. C., et al. (2007). Identification of acceptor substrate binding subsites +2 and +3 in the amylomaltase from Thermus thermophilus HB8†. Biochemistry, 46(17), $5261-5269$.

Kelly, R. M., Dijkhuizen, L., \& Leemhuis, H. (2009). Starch and $\alpha$-glucan acting enzymes, modulating their properties by directed evolution. Journal of Biotechnology, 140(3-4), 184-193.

Kiel, J. A., Boels, J. M., Beldman, G., \& Venema, G. (1991). Molecular cloning and nucleotide 
sequence of the glycogen branching enzyme gene (glgB) from Bacillus stearothermophilus and expression in Escherichia coli and Bacillus subtilis. Molecular Genetics and Genomics, 230(1-2), 136-144.

Kim, E.-J., Ryu, S.-I., Bae, H.-A., Huong, N. T., \& Lee, S.-B. (2008). Biochemical characterisation of a glycogen branching enzyme from Streptococcus mutans: Enzymatic modification of starch. Food Chemistry, 110(4), 979-984.

Kittisuban, P., Lee, B.-H., Suphantharika, M., \& Hamaker, B. R. (2014). Slow glucose release property of enzyme-synthesized highly branched maltodextrins differs among starch sources. Carbohydrate Polymers, 107(0), 182-191.

Kong, X., Bertoft, E., Bao, J., \& Corke, H. (2008). Molecular structure of amylopectin from amaranth starch and its effect on physicochemical properties. International Journal of Biological Macromolecules, 43(4), 377-382.

Le, Q.-T., Lee, C.-K., Kim, Y.-W., Lee, S.-J., Zhang, R., Withers, S. G., et al. (2009). Amylolytically-resistant tapioca starch modified by combined treatment of branching enzyme and maltogenic amylase. Carbohydrate Polymers, 75(1), 9-14.

Lee, B.-H., Yan, L., Phillips, R. J., Reuhs, B. L., Jones, K., Rose, D. R., et al. (2013). Enzymesynthesized highly branched maltodextrins have slow glucose generation at the mucosal $\alpha$-glucosidase level and are slowly digestible in vivo. PLOS ONE, 8(4), e59745.

Lee, B.-H., Bello-Pérez, L. A., Lin, A. H.-M., Kim, C. Y., \& Hamaker, B. R. (2013). Importance of location of digestion and colonic fermentation of starch related to its quality. Cereal Chemistry Journal, 90(4), 335-343.

Lee, C.-K., Le, Q.-T., Kim, Y.-H., Shim, J.-H., Lee, S.-J., Park, J.-H., et al. (2008). Enzymatic 
synthesis and properties of highly branched rice starch amylose and amylopectin cluster. Journal of Agricultural and Food Chemistry, 56(1), 126-131.

Lin, A. H.-M., Nichols, B. L., Quezada-Calvillo, R., Avery, S. E., Sim, L., Rose, D. R., et al. (2012). Unexpected high digestion rate of cooked starch by the Ct-maltase-glucoamylase small intestine mucosal $\alpha$-glucosidase subunit. PLoS ONE, 7(5), e35473.

Lin, A. H.-M., Nichols, B. L., Quezada-Calvillo, R., Rose, D. R., Sim, L., \& Hamaker, B. R. (2010). Specific starch digestion of maize alpha-limit dextrins by recombinant mucosal glucosidase enzymes. The FASEB Journal, 24, 231-236.

Nelson, N. (1944). A photometric adaptation of the Somogyi method for the determination of glucose. Journal of Biological Chemistry, 153(2), 375-380.

Patil, N. B. (1976). Beta-amylase-resistant amylose: Effect of urea on the limited hydrolysis of amylose by beta-amylase. Biochemical Journal, 153(2), 339-342.

Pérez, S., \& Bertoft, E. (2010). The molecular structures of starch components and their contribution to the architecture of starch granules: A comprehensive review. Starch Stärke, 62(8), 389-420.

Rolland-Sabaté, A., Guilois, S., Jaillais, B., \& Colonna, P. (2011). Molar mass and mass distributions of native starches using complementary separation methods: Asymmetrical Flow Field Flow Fractionation (A4F) and Hydrodynamic and Size Exclusion Chromatography (HDC-SEC). Analytical and Bioanalytical Chemistry, 399(4), 14931505.

Roussel, X., Lancelon-Pin, C., Viksø-Nielsen, A., Rolland-Sabaté, A., Grimaud, F., Potocki- 
Véronèse, G., et al. (2013). Characterization of substrate and product specificity of the purified recombinant glycogen branching enzyme of Rhodothermus obamensis. Biochimica et Biophysica Acta (BBA) - General Subjects, 1830(1), 2167-2177.

Shaik, S. S., Carciofi, M., Martens, H. J., Hebelstrup, K. H., \& Blennow, A. (2014). Starch bioengineering affects cereal grain germination and seedling establishment. Journal of Experimental Botany, 65(9), 2257-2270.

Shinohara, M., Ihara, M., Abo, M., Hashida, M., Takagi, S., \& Beck, T. (2001). A novel thermostable branching enzyme from an extremely thermophilic bacterial species, Rhodothermus obamensis. Applied Microbiology and Biotechnology, 57(5-6), 653-659.

Sim, L., Willemsma, C., Mohan, S., Naim, H. Y., Pinto, B. M., \& Rose, D. R. (2010).

Structural basis for substrate selectivity in human maltase-glucoamylase and sucraseisomaltase N-terminal domains. Journal of Biological Chemistry, 285(23), 17763-17770.

Sorndech, W., Meier, S., Jansson, A. M., Sagnelli, D., Hindsgaul, O., Tongta, S., et al. (2015). Synergistic amylomaltase and branching enzyme catalysis to suppress cassava starch digestibility. Carbohydrate Polymers, 132, 409-418.

Takata, H., Takaha, T., Nakamura, H., Fujii, K., Okada, S., Takagi, M., et al. (1997). Production and some properties of a dextrin with a narrow size distribution by the cyclization reaction of branching enzyme. Journal of Fermentation and Bioengineering, 84(2), 119-123.

Takata, H., Takaha, T., Okada, S., Hizukuri, S., Takagi, M., \& Imanaka, T. (1996). Structure of the cyclic glucan produced from amylopectin by Bacillus stearothermophilus branching enzyme. Carbohydrate Research, 295(0), 91-101.

Takata, H., Takaha, T., Okada, S., Takagi, M., \& Imanaka, T. (1996). Cyclization reaction 
catalyzed by branching enzyme. Journal of Bacteriology, 178(6), 1600-1606.

Tharanathan, R. N. (2005). Starch — Value addition by modification. Critical Reviews in Food Science and Nutrition, 45(5), 371-384.

van der Maarel, M. J. E. C., Capron, I., Euverink, G. J. W., Bos, H. T., Kaper, T., \& Binnema, D. J. (2005). A novel thermoreversible gelling product made by enzymatic modification of starch. Starch - Stärke, 57, 465-472.

Vasanthan, T. (2001). Current protocols in food analytical chemistry. New York: John Wiley \& Sons, Inc.

Viksø-Nielsen, A., Blennow, A., Nielsen, T. H., \& Møller, B. L. (1998). Phosphorylated $\alpha(1 \rightarrow 4)$ glucans as substrate for potato starch-branching enzyme I. Plant Physiology, 117, 869-875.

Wood, L. F., \& Mercier, C. (1978). Molecular structure of unmodified and chemically modified manioc starches. Carbohydrate Research, 61(1), 53-66.

Zhang, G., Ao, Z., \& Hamaker, B. R. (2006). Slow digestion property of native cereal starches. Biomacromolecules, 7(11), 3252-3258. 

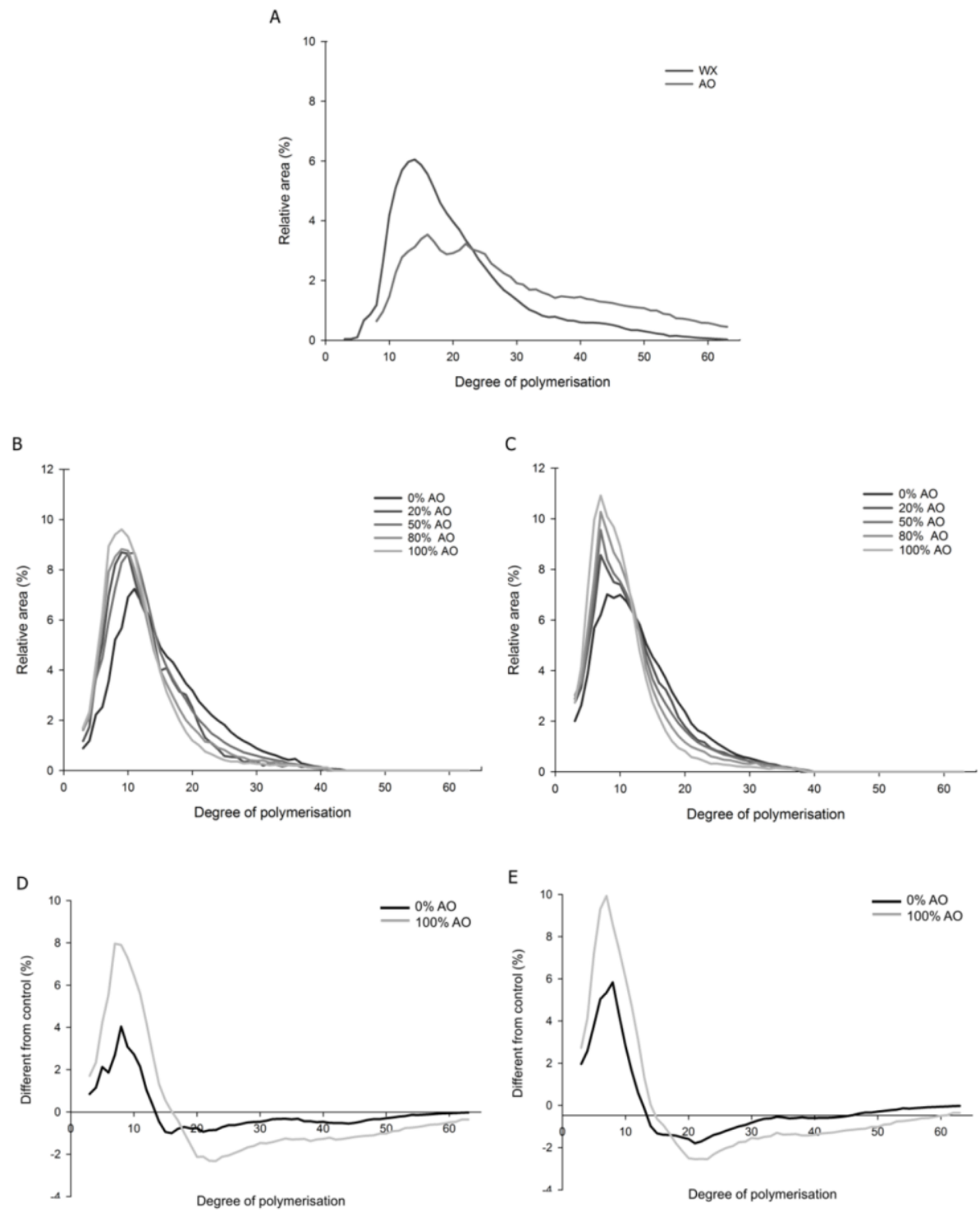

Fig. 1. Relative area (\%) of debranched glucan samples. (A) WX and AO control substrates, (B) $\mathrm{BE}$ treated sample, (C) $\mathrm{BE} \rightarrow \mathrm{AM} \rightarrow \mathrm{BE}$ treated sample with specific AO content. (D-E) Difference plots relative to controls as indicated, (D) BE treated samples as compared to corresponding control $\mathrm{WX}$ and $\mathrm{AO}$ substrates, (E) $\mathrm{BE} \rightarrow \mathrm{AM} \rightarrow \mathrm{BE}$ treated samples as compared to control WX and AO. WX, waxy maize starch; AO, amylose only barley starch; BE, branching enzyme-treated starch; and $\mathrm{BE} \rightarrow \mathrm{AM} \rightarrow \mathrm{BE}$, sequential enzyme treatments. 
A

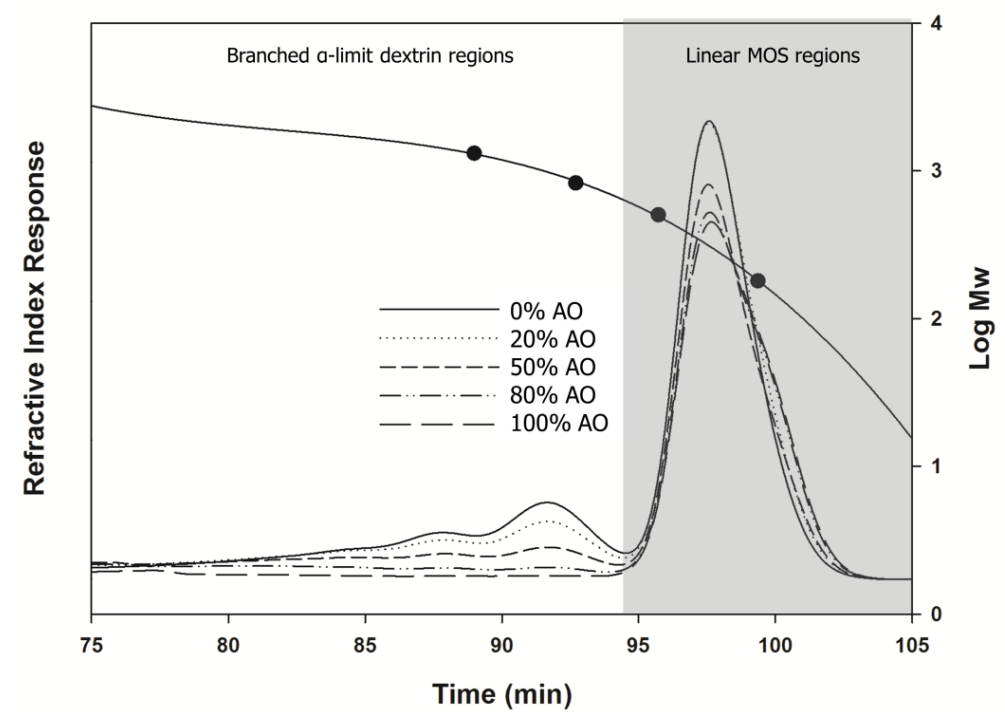

B

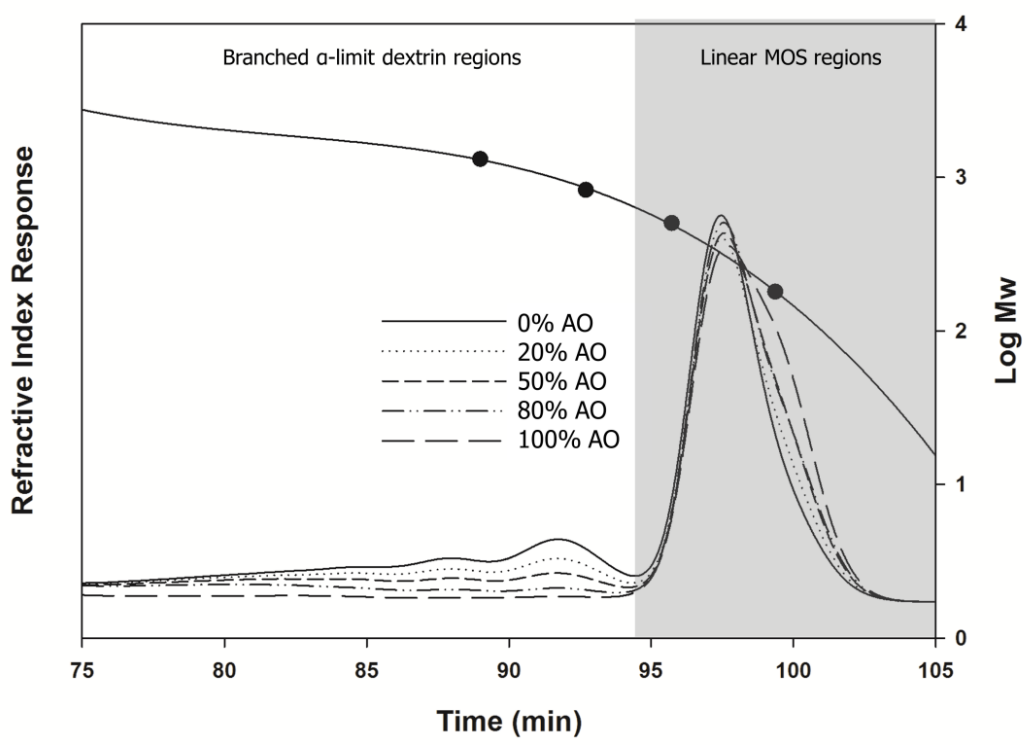

Fig. 2. Molar mass distribution of enzyme-modified starches by HPSEC-RI after human pancreatic $\alpha$-amylase treatment. The two different regions indicate branched and linear $\alpha$-limit dextrins, respectively, as verified elsewhere (Lee et al., 2013). The peak area of branched $\alpha$-limit dextrins are interpreted in Table 4. A) BE treated samples and B) $\mathrm{BE} \rightarrow \mathrm{AM} \rightarrow \mathrm{BE}$ treated samples. Log $\bar{M}_{w}$ corresponds to the $\bar{M}$ w calculated with strictly linear pullulan standards. 

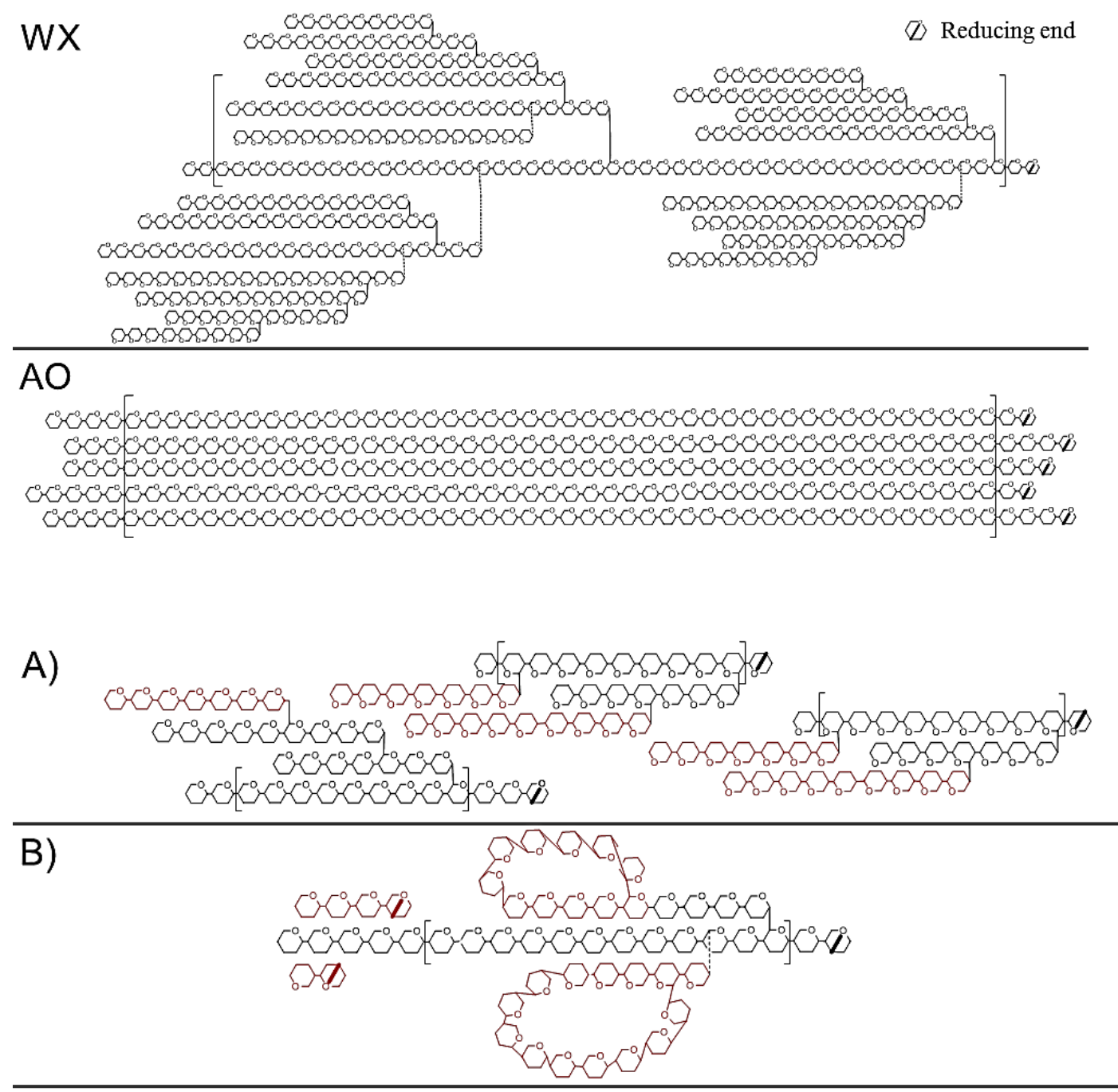

C)

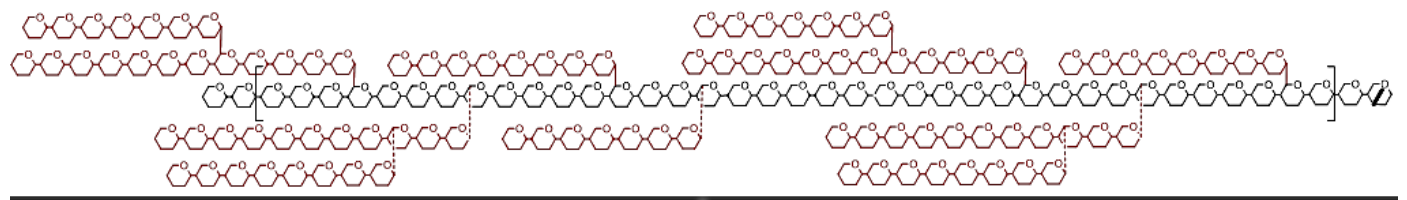

D)

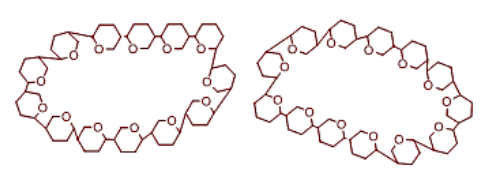

E)

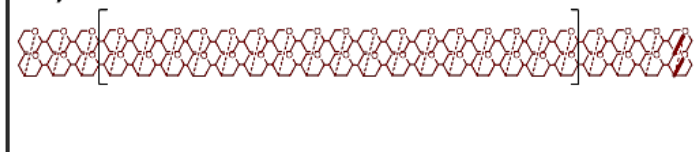

Fig. 3. Schematic representation the obtained products from $B E$ and $B E \rightarrow A M \rightarrow B E$ reaction. The black symbol symbolize $\alpha$-D-glucose unit and red symbol symbolize newly generated $\alpha$ glucan. A-B represents enzymes-treated WX products, A: branched-amylopectin cluster, B: cyclo-amylopectin cluster and short $\alpha$-glucan chains. C-E: represents enzymes-treated AO products, C: branched-amylose, D: cyclo-amylose and E) amylose double helix. 
Table 1. Content (\%) and the increased ratio of $\alpha-1,6$ linkages of the enzyme-modified starches. WX, waxy maize starch; AO, amylose-only barley starch; BE, branching enzyme-treated starch; and $\mathrm{BE} \rightarrow \mathrm{AM} \rightarrow \mathrm{BE}$, starch treated with branching enzyme followed by amylomaltase and completed with branching enzyme.

\begin{tabular}{|c|c|c|c|}
\hline $\begin{array}{c}\text { Samples/ } \\
\text { Enzymes } \\
\text { treatment }\end{array}$ & $\begin{array}{c}\text { AO } \\
\text { content } \\
(\boldsymbol{\%})\end{array}$ & $\begin{array}{c}\boldsymbol{\alpha}-\mathbf{1 , 6} \\
(\boldsymbol{\%})\end{array}$ & $\begin{array}{c}\text { Increase in ratio } \\
\text { of } \boldsymbol{\alpha - 1 , 6} \text { (fold)** }\end{array}$ \\
\hline WX & 0 & 3.5 & - \\
\hline AO & 100 & $0.2 *$ & - \\
\hline \multirow{5}{*}{$\mathrm{BE}$} & 0 & 8.7 & 1.5 \\
\cline { 2 - 4 } & 20 & 8.4 & 2.0 \\
\cline { 2 - 4 } & 50 & 8.2 & 3.4 \\
\cline { 2 - 4 } & 80 & 7.2 & 7.4 \\
\cline { 2 - 4 } & 100 & 7.0 & 34.0 \\
\hline \multirow{5}{*}{$\mathrm{BE} \rightarrow \mathrm{AM} \rightarrow \mathrm{BE}$} & 0 & 9.7 & 1.8 \\
\cline { 2 - 4 } & 20 & 8.9 & 2.1 \\
\cline { 2 - 4 } & 50 & 8.7 & 3.7 \\
\cline { 2 - 4 } & 80 & 8.5 & 8.9 \\
\cline { 2 - 4 } & 100 & 8.0 & 39.0 \\
\hline
\end{tabular}

*Degree of branching calculated from ${ }^{1} \mathrm{H}-\mathrm{NMR}$ except for the AO substrate, which was determined by reducing end analysis.

**The increment of $\alpha-1,6$ as compared to the initial values calculated from the substrate mixture ratios (Supplementary Table 1). 
Table 2. Average chain length distribution (\%) of $\alpha$-glucan products and control AO and WX starches.

\begin{tabular}{|c|c|c|c|c|c|c|c|c|c|c|c|c|}
\hline \multirow{2}{*}{$\begin{array}{c}\% \\
\text { Distribution }\end{array}$} & \multirow[b]{2}{*}{$\mathbf{W X}$} & \multirow[b]{2}{*}{ AO } & \multicolumn{5}{|c|}{ BE treated } & \multicolumn{5}{|c|}{$\mathrm{BE} \rightarrow \mathrm{AM} \rightarrow \mathrm{BE}$ treated } \\
\hline & & & $\begin{array}{l}\text { 0\% } \\
\text { AO }\end{array}$ & $\begin{array}{c}20 \% \\
\text { AO }\end{array}$ & $\begin{array}{c}50 \% \\
\text { AO }\end{array}$ & $\begin{array}{r}80 \% \\
\text { AO }\end{array}$ & $\begin{array}{c}100 \% \\
\text { AO }\end{array}$ & $\begin{array}{l}0 \% \\
\text { AO }\end{array}$ & $\begin{array}{r}20 \% \\
\text { AO }\end{array}$ & $\begin{array}{r}50 \% \\
\text { AO }\end{array}$ & $\begin{array}{r}80 \% \\
\text { AO }\end{array}$ & $\begin{array}{c}100 \% \\
\text { AO }\end{array}$ \\
\hline DP 3-12 & 20.5 & 14.6 & 42.2 & 58.6 & 58.5 & 62.5 & 67.8 & 54.3 & 61.9 & 65.0 & 70.6 & 77.7 \\
\hline DP $13-24$ & 54.2 & 37.8 & 45.6 & 36.7 & 40.0 & 31.9 & 28.4 & 37.9 & 32.8 & 29.8 & 25.3 & 19.8 \\
\hline DP $25-36$ & 16.6 & 22.0 & 11.2 & 4.1 & 7.2 & 5.1 & 3.3 & 6.5 & 5.2 & 5.1 & 3.8 & 2.3 \\
\hline $\mathrm{DP}>37$ & 8.7 & 25.6 & 1.0 & 0.7 & 0.7 & 0.5 & 0.7 & 0.3 & 0.1 & 0.2 & 0.3 & 0.2 \\
\hline
\end{tabular}

WX, waxy maize starch; AO, amylose only barley starch; BE, branching enzyme-treated starch; and $\mathrm{BE} \rightarrow \mathrm{AM} \rightarrow \mathrm{BE}$, sequential enzyme treatments. 
Table 3. Molar mass distribution $\left(\overline{\mathrm{M}}_{\mathrm{w}}\right)$, hydrodynamic radius $\left(\mathrm{R}_{\mathrm{h}}\right)$, dispersity index $\left(\overline{\mathrm{M}}_{\mathrm{w}} / \overline{\mathrm{M}}_{\mathrm{n}}\right)$, intrinsic viscosity (IV) and molecular density of the control and enzyme-modified starches. AF4MALLS was used for AO and WX while SEC (Viscotek-TDA system) was used for enzymemodified starches.

\begin{tabular}{|c|c|c|c|c|c|}
\hline $\begin{array}{l}\text { Enzymes } \\
\text { treatment }\end{array}$ & $\begin{array}{c}\text { AO } \\
\text { content } \\
(\%)\end{array}$ & $\begin{array}{c}\bar{M}_{w} \\
\left(\mathbf{x} 10^{3} \mathrm{~g} \cdot \mathrm{mol}^{-1}\right)\end{array}$ & $\mathbf{R}_{\mathbf{h}}(\mathbf{n m})$ & $\overline{\mathrm{M}}_{\mathrm{w}} / \overline{\mathrm{M}}_{\mathrm{n}}$ & $\begin{array}{c}\text { Molecular } \\
\text { density } \\
\left(\mathbf{g} \cdot \mathbf{m o l}^{-1} \cdot \mathbf{n m}^{-3}\right)\end{array}$ \\
\hline $\mathrm{WX} *$ & 0 & 399,000 & N.A. & 1.4 & N.A. \\
\hline $\mathrm{AO}^{*}$ & 100 & 5,500 & N.A. & 6.2 & N.A. \\
\hline \multirow{5}{*}{$\mathrm{BE}$} & 0 & 154 & 12.5 & 1.7 & 18.8 \\
\hline & 20 & 175 & 13.3 & 1.6 & 17.8 \\
\hline & 50 & 261 & 15.2 & 1.6 & 17.7 \\
\hline & 80 & 426 & 17.9 & 1.6 & 17.7 \\
\hline & 100 & 1,000 & 27.1 & 1.6 & 12.0 \\
\hline \multirow{5}{*}{$\mathrm{BE} \rightarrow \mathrm{AM} \rightarrow \mathrm{BE}$} & 0 & 166 & 13.0 & 2.9 & 18.0 \\
\hline & 20 & 291 & 15.9 & 2.6 & 17.3 \\
\hline & 50 & 368 & 17.3 & 1.4 & 17.0 \\
\hline & 80 & 517 & 19.1 & 1.8 & 17.7 \\
\hline & 100 & 912 & 23.9 & 2.0 & 15.9 \\
\hline
\end{tabular}

*The radius of gyration, Rg for WX and AO are 281.0 and $139.0 \mathrm{~nm}$, respectively. N.A.; Not Available. 
Table 4. The peak area $(\%)$ of branched $\alpha$-limit dextrin regions after human pancreatic $\alpha$ amylase digestion from Fig. 2 compared to the $\beta$-amylolysis limit.

\begin{tabular}{|c|c|c|c|}
\hline $\begin{array}{l}\text { Samples/ } \\
\text { Enzymes } \\
\text { treatment }\end{array}$ & $\begin{array}{c}\text { AO content } \\
(\%)\end{array}$ & $\begin{array}{l}\text { Area for branched } \\
\alpha \text {-limit dextrin }(\%)\end{array}$ & $\begin{array}{c}\beta \text {-amylolysis } \\
\text { limit }(\%)\end{array}$ \\
\hline WX & 0 & 27.0 & 47.9 \\
\hline $\mathrm{AO}$ & 100 & 3.8 & 64.8 \\
\hline \multirow{5}{*}{$\mathrm{BE}$} & 0 & 32.3 & 33.3 \\
\hline & 20 & 27.8 & 29.3 \\
\hline & 50 & 23.6 & 25.8 \\
\hline & 80 & 14.3 & 21.1 \\
\hline & 100 & 6.5 & 20.0 \\
\hline \multirow{5}{*}{$\mathrm{BE} \rightarrow \mathrm{AM} \rightarrow \mathrm{BE}$} & 0 & 34.5 & 21.4 \\
\hline & 20 & 29.5 & 18.7 \\
\hline & 50 & 23.1 & 14.7 \\
\hline & 80 & 14.9 & 13.2 \\
\hline & 100 & 7.3 & 12.2 \\
\hline
\end{tabular}


Table 5. Glucose released (\%) from enzyme modified starches and control starch by human pancreatic $\alpha$-amylase followed by rat intestinal $\alpha$-glucosidases. The AO:WX ratios indicated are for the original substrates prior to enzyme treatment.

\begin{tabular}{|c|c|l|}
\hline $\begin{array}{c}\text { Samples/ } \\
\text { Enzyme } \\
\text { treatment }\end{array}$ & $\begin{array}{c}\text { AO } \\
\text { content } \\
(\%)\end{array}$ & $\begin{array}{c}\text { Glucose } \\
\text { released }(\%)\end{array}$ \\
\hline WX & 0 & $51.0 \pm 3.0^{\mathrm{bcd}}$ \\
\hline AO & 100 & $26.0 \pm 3.0^{\mathrm{g}}$ \\
\hline \multirow{4}{*}{ BE } & 0 & $58.0 \pm 0.0^{\mathrm{a}}$ \\
\cline { 2 - 3 } & 20 & $56.0 \pm 2.0^{\mathrm{ab}}$ \\
\cline { 2 - 3 } & 50 & $53.0 \pm 1.0^{\mathrm{abc}}$ \\
\cline { 2 - 3 } & 80 & $50.0 \pm 1.0^{\mathrm{bcd}}$ \\
\cline { 2 - 3 } & 100 & $43.0 \pm 1.0^{\mathrm{ef}}$ \\
\hline \multirow{4}{*}{$\mathrm{BE} \rightarrow \mathrm{AM} \rightarrow \mathrm{BE}$} & 0 & $51.0 \pm 1.0^{\mathrm{bcd}}$ \\
\cline { 2 - 3 } & 20 & $48.0 \pm 2.0^{\mathrm{cde}}$ \\
\cline { 2 - 3 } & 50 & $45.0 \pm 1.0^{\mathrm{ef}}$ \\
\cline { 2 - 3 } & 80 & $43.0 \pm 1.0^{\mathrm{ef}}$ \\
\cline { 2 - 3 } & 100 & $38.0 \pm 1.0^{\mathrm{f}}$ \\
\hline
\end{tabular}

